TITRE: THE DEVELOPMENT OF PHONEME AWARENESS AND LETTER KNOWLEDGE: A TRAINING STUDY OF CZECH PRESCHOOL CHILDREN.

Auteur(s): Gabriela Seidlová Málková, Faculty of Humanities, Charles University Prague, CZECH REPUBliC \& MARKÉTA CARAVOLAS, SCHOOL OF PSYCHOLOGY, BANGOR UNIVERSITY, UNITED KINGDOM

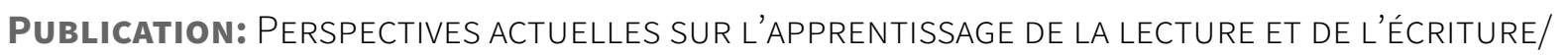
CONTRIBUTIONS ABOUT LEARNING TO READ AND WRITE - ACTES DU SYMPOSIUM INTERNATIONAL SUR LA LITÉRACIE À L'ÉCOLE/INTERNATIONAL SYMPOSIUM FOR EDUCATIONAL LITERACY (SILE/ISEL) 2015

PAGES: $31-56$

Directeurs: Marie-France Morin, Denis Alamargot et Carolina Gonçalves.

É́dITEUR: LES ÉDITIONS DE L'UNIVERSITÉ DE SHERBROOKE, 2016.

ISBN: 978-2-7622-0355-4

URI: HTTP://HDL.HANDLE.NET/11143/10227

DOI: HTTPS://DOI.ORG/10.17118/11143/10227 


\title{
The development of phoneme awareness and letter knowledge: A training study of Czech preschool children
}

\author{
Gabriela Seidlová Málková, Faculty of Humanities, Charles University Prague, Czech Republic \\ Markéta Caravolas, School of Psychology, Bangor University, United Kingdom
}

\begin{abstract}
We investigated phoneme awareness (PA) and letter knowledge (LK) development among Czech preschool children, in the context of a training study. One hundred and eighty-one preliterate children aged 4.5-5 years were randomly assigned to a 7-week PA or LK training programme, or to an untreated Control group. All groups were pre-tested on measures of PA, LK, reading and nonverbal IQ and re-tested at the end of training. The distributional properties of PA and LK were examined to understand the emergence of each skill in the absence of training and after training. The impact of each training programme on the development of PA and LK was assessed, controlling for autoregressive effects, using ANCOVA. Both skills improved with direct training, but seemed to be separately arising and subject to different developmental influences. Growth in PA was predicted in all groups by earlier levels of PA, but not by earlier LK. Growth in LK was predicted in all groups by earlier levels of LK and PA.
\end{abstract}

Keys words: phoneme awareness, letter knowledge, preschool children, training study

Résumé : Cette étude a porté sur le développement de la conscience phonémique (CP) et de la connaissance des lettres (CL) chez les enfants tchèques d'âge préscolaire, dans le cadre d'une étude d'entrainement. Cent quatre-vingt-un enfants non lecteurs (âgés de 4,5-5 ans) ont été assignés au hasard à un programme d'entrainement quotidien durant 7 semaines, soit en CP ou CL, ou à un groupe témoin non traité. Tous les groupes ont été testés au préalable, et re-testés immédiatement après la fin de la formation, sur la conscience phonémique, la connaissance des lettres (reconnaissance et écriture), la lecture et la capacité non verbale. Les caractéristiques distributives de chaque compétence ont été examinées avant et après l'entrainement. L'impact de chaque formation sur le développement de CP et CL a été évalué, en contrôlant les effets autorégressifs, avec ANCOVA. Les deux compétences ont bénéficié d'un entrainement ciblé, mais chacune semblait être sensible aux influences développementales distinctes. La croissance de la CP a été prédite dans tous les groupes par les niveaux antérieurs de CP, mais pas par la CL. La croissance de la CL a été prédite dans tous les groupes par les niveaux antérieurs de CP et CL.

Mots clés : conscience phonémique, connaissance des lettres, enfants d'âge préscolaire, étude d'entrainement 


\section{Background}

It is now well established in different languages with alphabetic orthographies, that letter knowledge and phoneme awareness are important prerequisite skills that work in reciprocal alliance to promote beginning reading in children (see review in Caravolas \& Samara, 2015). By letter knowledge, we mean the ability to recognize and pronounce letters by their sounds and names, as well as to write letters to dictation. Typically, preschool children learning alphabetic orthographies know some letters before they are taught formally in school, although differences exist in the extent to which informal letter learning practices occur in different countries (e.g., Caravolas et al., 2012; Hulme, Caravolas, Málková, \& Bridgstocke, 2005; Levin, Patel, Margalit, \& Barad, 2002; Treiman Jackiw, \& Gross, 2015). In this paper, we use the term letter knowledge as "an umbrella" term that includes knowledge of both letter sounds and letter names. Phoneme awareness refers to a variety of meta-linguistic skills, requiring explicit or implicit awareness of the smallest unit of spoken language:the phoneme (e.g., Gillon, 2004). It develops gradually throughout childhood, but accelerates in the preschool years. In general, children are said to progress from having implicit phonological knowledge, that for example enables a child to discriminate acceptable and unacceptable variations of a spoken word, through to the capacity to explicitly manipulate phonemes in words. A long-standing question asks what creates children ability to manipulate phonemes, given the abstract and variable nature of these speech units (Bentin, 1992; Castles \& Coltheart, 2004; Fowler, 1991). Three main theoretical hypotheses have been proposed to explain the origins of the strong developmental association of phoneme awareness and letter knowledge.

Reading as the precursor to phoneme awareness. The first position claims, that children become explicitly aware of the phonemic structure of words as a direct result of learning to read alphabetic orthographies. In this view, a prerequisite to the emergence of phoneme awareness is the understanding of the alphabetic principle that written words are composed of alphabetic letters which correspond to more or less invariant speech sounds (i.e., phonemes). A number of empirical studies support this position (e.g., Adrián, Alegria, \& Morais, 1995; Duncan, Colé, Seymour, \& Magnan, 2006; Libermann, Shankweiler, Fischer, \& Carter, 1974; Morais, Cary, Alegria, \& Bertelson, 1979; Read, Zhang, Nie, \& Ding, 1986), typically with data from preliterate children or illiterate adults. For example, illiterate adults are less able than their literate peers to respond to meta-phonological tasks at the level of phonemes (Adrián et al., 1995; Morais et al., 1979). Such results led Adrián et al. (1995, p. 17) to conclude that "Phonological sensitivity may be a universal capacity, whereas phonemic awareness is dependent on learning to read and write an alphabetic notation...., In a cross-sectional study comparing French and English children on awareness of syllables, rimes and phonemes, Duncan et al. (2006) reported that despite cross-linguistic differences in syllable and rime awareness in the preschool years, both language groups demonstrated a marked increase in phoneme awareness only in Grade 1. Two subsequent reviews strongly argued in favour of the role of orthographic knowledge as a possible foundation for phoneme awareness. According to Castles \& Coltheart (2004), acquiring letter-sound knowledge in the process of learning to read enables children to manipulate phone- 
mes because they are capable of manipulating orthographic images of words. Similarly, Ziegler and Goswami's (2005) psycholinguistic grain size theory of literacy development argues that acquisition of phoneme awareness is dependent on reading and spelling instruction: "Full access to phonemes only develops once children are taught to read and write, irrespective of the age at which reading and writing is taught." (p. 4). However, the strong hypothesis that learning to read is the cause of phoneme awareness is weakened by findings such as the fact that the illiterate adults in Morais and Alegria's studies attained poor (appx. 20\% accuracy) but not null results in phoneme deletion skill. Similarly, results from studies with not-yet-literate young children from a variety of language backgrounds demonstrate that most can deal with phoneme awareness tasks to some extent before they start to learn letters in school (e.g., Caravolas \& Bruck, 1993, for Czech; Hulme et al., 2005, for English and Czech; Cossu, Shankweiler, Liberman, Katz \& Tola, 1988, for Italian). Even the study by Duncan et al. (2006) reports that French and English pre-schoolers as young as four years of age showed measurable levels of phoneme awareness (16 - 29\%) in certain contexts.

Letter knowledge as the precursor to phoneme awareness. A related, yet more specific hypothesis regarding the developmental relationship of phoneme awareness and letter knowledge could be labelled the letter knowledge first hypothesis. In this variant, letter knowledge is necessary and sufficient to cause the development of phoneme awareness. Letter knowledge is thus? thought to have a direct as well as an indirect effect via phoneme awareness on beginning reading (and spelling). Empirical data supporting this hypothesis were reported by Lukatela, Carello, Shankweiler, and Liberman (1995) in their study with illiterate Serbo-Croatian women. These authors argued for the crucial role of spontaneously acquired letter knowledge in the development of beginning reading, which in their view works as a stimulus for the development of phoneme awareness especially in languages with highly transparent orthographies like Serbo-Croatian: „Some almost totally unschooled speakers of this language can penetrate remarkably far into the orthography, armed only with phonological awareness and alphabetic knowledge. We suggest that for a Serbo-Croatian speaker, knowing the letter units is the entry point into the alphabetic principle because letters and phonemes are related so straightforwardly." (p. 17). However, a similar view has also been put forward for child learners of the inconsistent English orthography (e.g., Johnston, Anderson, \& Holligan, 1996), and is well captured within the framework of Roderrick Barron's (1998) concept of "proto-literacy". This refers to the emergent knowledge about associations between letters and their sounds, which, according to Barron, is the first evidence, that children make a connection between print and speech at the sub-syllabic level (the level essential for understanding the alphabetic principle). Moreover, this proto-literacy functions as a facilitator in the process of becoming aware of phonemes in words (Barron, 1991, p. 159-165). 
The dual foundation hypothesis. The above hypotheses contrast with studies demonstrating that preschool children who do not know any letters or only a few, are able to manipulate phonemes in words. Hulme et al. (2005) demonstrated this fact for English and also for Czech speaking pre-literate children. Approximately $90 \%$ of Czech and $80 \%$ of English children aged 4.5 to 5.5 years could manipulate at least one phoneme for which they did not know corresponding letter, and, $80 \%$ of Czech children could do this with at least 5 phonemes. This study showed that phoneme awareness could not be understood as simple consequence of reading ability or letter knowledge.

Results of the Hulme et al. (2005) study bring us to the third theoretical position which sees phoneme awareness and letter knowledge as two separate precursors - or the dual foundation - of alphabetic literacy (Byrne, 1998). Phoneme awareness and letter knowledge are thus assumed to develop in a reciprocal and mutually beneficial relationship. A number of large-scale, longitudinal studies of reading and spelling development provide strong endorsement of this view. For example Mutter, Hulme, Snowling and Taylor (1997) found that four-year-old British children's levels of phoneme awareness and letter knowledge were unique and independent longitudinal predictors of later reading, but, over and above their independent predictive roles, phoneme awareness predicted later growth in letter knowledge and conversely early letter knowledge predicted later phoneme awareness. The authors thus concluded that: ,it is not simply having adequate letter knowledge or adequate phonological skills that permits good progress in learning to read, rather both these factors are important and they act in an interactive fashion..." (p. 389). A very similar pattern between phoneme awareness and letter knowledge was observed in the context of British children's early spelling development in a study by Caravolas, Hulme and Snowling (2001). Burgess and Lonigan's (1998) study of early reading development with American English speaking 4 - 5-year-old children, observed the reciprocal relationship prior any rudimentary decoding skill, even when controlling for children's age and oral language abilities. More recently, in two multi-language, longitudinal studies, Caravolas et al. (2012; 2013) demonstrated that phoneme awareness and letter knowledge uniquely contributed to early reading and spelling development not only among English, but also among Spanish, Slovak, and Czech preschool children. While these studies did not test for the presence of a reciprocal relationship between the skills, they confirmed that the relative importance of each skill to later reading and spelling was similar across these disparate languages.

Intervention studies. Several short training studies were carried out in the 1980s and 1990s to better understand the relative impact of letter knowledge and phoneme awareness, respectively, on later reading development, and these revealed that it is the training of the two skills in tandem that produced the greatest benefits for reading development (e.g., Ball \& Blachman, 1991; Bradley \& Bryant, 1983). Probing this relationship further, Hulme, Bowyer-Crane, Carroll, Duff, \& Snowling (2012) carried out an intervention study with English-speaking four-year-old pre-schoolers who were selected for participation due to weak oral language skills, and then were randomly assigned to a 20-week intervention comprising either training in phoneme awareness, letter knowledge and basic reading skills, or oral language comprehension and vocabulary skills. This study elegantly showed that only 
the children receiving the phonemic and letter knowledge intervention made significant progress in reading at the end of the study, and their reading performance was fully mediated by phoneme awareness and letter knowledge levels attained during the training program.

In an experimental training study focusing more specifically on the respective contributions of each skill, Castles, Coltheart, Wilson, Valpied and Wedgwood (2009) examined whether letter awareness (that is, awareness of visual forms of letters) or phoneme awareness in preliterate children directly assisted them in learning letter-sound correspondences. Eighty-seven Australian preschool children aged 3 to 5 years were randomly assigned to a phoneme awareness group, a letter awareness group, or an untreated control group for a phase one training, which lasted 6 months. Phase two training comprised another six weeks, this time with activities to foster letter-sound correspondences. The authors reported that phoneme awareness training was very effective, bringing large and significant effects that generalized over trained phonemes. Letter awareness training was reported to be less effective, bringing generally weaker effects and limited generalization to untrained letters. Moreover, the phase two training results indicated that the letter shape training in phase was not effective in bolstering letter-sound learning. Phoneme awareness training was partially effective in that it was associated with better ability to recognize letters based on their sounds, but not with the ability to generate pronunciations based on visual letter prompts. The authors concluded that children who have no orthographic knowledge could be taught to perform the phoneme awareness tasks. However ..."when orthographic skills are present they play a significant role in children's performance on tasks traditionally used to measure phonemic awareness ... (and that)....letter-sound correspondences can be successfully taught to preschoolers even in the absence of measurable phonemic awareness..." (p. 85).

In sum, in contrast with predictions that arise from the 'reading first' and the 'letter knowledge first' hypotheses, that phoneme awareness arises as a consequence of either or both of these skills, the above longitudinal and training studies demonstrated that phoneme awareness can not only precede, but also independently promote letter knowledge and in turn reading/spelling abilities. While longitudinal, regression-based studies in a variety of languages now confirm the importance of both phoneme awareness and letter knowledge as foundation of literacy skills, the intervention and training studies exploring their relationship in English are not fully consistent with each other (Castles et al., 2009; Hulme et al., 2012). Thus, we carried out an intervention study to further examine this relationship among pre-school learners of Czech. This group is of interest because several studies have found Czech pre-schoolers to have relatively good phoneme awareness, despite knowing few or no letters (e.g., Caravolas \& Bruck, 1993; Caravolas \& Landerl, 2010; Hulme et al., 2005). In addition, Czech has an orthography that is highly consistent in phoneme-grapheme mappings, and it has previously been argued that in consistent orthographies, phoneme awareness is a less important precursor skill because children can rely almost exclusively on their letter sound knowledge to learn the alphabetic principle and to progress in reading skills (e.g., see the seminal paper on this issue by Wimmer, Landerl, Linortner \& Hummer, 1991; also Lukatela et al., 1995). 


\section{Aims of this study}

Starting with the assumption that phoneme awareness and letter knowledge each represent an essential foundation skill for alphabetic reading development, we investigated the extent to which the two skills and their inter-relationship can be promoted through training in a practical educational setting. In contrast to studies where the links between phonemes and letters were explicitly trained (e.g., Ball \& Blachman, 1991; Hatcher, Hulme \& Ellis, 1994; Hulme et al., 2012), we conducted separate training programmes in phoneme awareness and in letter knowledge among Czech preschool children at a point in development where they had no measurable reading skills. Our approach also differed from that of Castles et al. (2009), who trained awareness of letters in the absence of their associated sounds (phase one). While we also focused the letter training programme on letter shapes/ formation, and the associations between letters and their corresponding phonemes were not explicitly taught, children were incidentally exposed to letter sound information through several training activities. Notably, however, children receiving the phoneme awareness training were not exposed to letters at all. Our aim was, first, to gain a deeper understanding of how each skill emerges prior to intervention, and then is shaped by learning experiences; that is, by the presence or absence of targeted training. To this end, we compared the distributional patterns of phoneme awareness and letter knowledge across intervention groups and an untrained control group, at baseline and at the end of the intervention period. Moreover, we aimed to assess the effectiveness of each implemented training on gains in the targeted skills. (To note, we originally aimed to also assess the impact of each training on eventual reading development, however, at the end of the intervention, all groups' reading levels were still at floor level - reflecting the preschool norms of no literacy teaching in Kindergarten in the Czech Republic. For this reason, we do not report any post-intervention reading data.) Finally, we also wanted to examine the mutual interrelationships between phoneme awareness and letter knowledge in the context of the different training situations.

\section{Method}

Eleven schools in Prague, and its suburbs were recruited, where teachers were interested in actively participating in the implementation of phoneme awareness and letter knowledge training programmes in their classrooms. We conducted a randomized controlled trial with children who received parental informed consent and who were clustered within participating schools. Approximately 15-30 participants in each school were randomly assigned to one of three conditions: the phoneme awareness intervention (PA), the letter knowledge intervention (LK) and the untreated control group (Control). Both interventions included 35 lessons and were delivered by the same teacher or pair of teachers in each school, every day for a period of 7 weeks. All participating teachers were trained in the delivery of the training programmes provided for the purpose of this study and were regularly supervised during the project. Children 's performance was assessed at pre-test, one or two weeks prior to the beginning of the intervention (T1), and at the end of the intervention (post-test/ 
T2). Intermediate and delayed post-tests were also carried out, but were beyond the scope of the present study.

\section{Participants}

Two-hundred-and-five Czech monolingual children from the above-mentioned kindergartens were recruited. For the purpose of our study, we retained children who knew few or no letters and who did not have fully developed phoneme awareness. Among Czech children, phoneme awareness rapidly develops between 5.5 and 6 years of age, and a typical 5.5-year-old child knows quite a few letters. Caravolas et al. (2012), found Czech 6-year-old kindergarteners to know on average 22 letter sounds and eight letter names, while Hulme et al. (2005) reported that Czech 4 - 5 year-old pre-schoolers recognized on average three and wrote on average two letters. For this reason we sought to recruit younger children, 4.5 to 5 years of age. Of the initial sample, five children were unavailable for pre testing, and 11 children with disproportionately high reading ability at the beginning of the study were excluded. In addition, another 11 children who knew disproportionately many letters - that is, whose aggregated letter knowledge scores (upper and lower case, letter sounds and names) were more than 2 standard deviations above the group mean - at pre-test were excluded. Table 1 describes the age statistics for the 181 children retained for the study.

Table 1. Descriptive statistics of age in months for children in each experimental group at pretest (T1).

\begin{tabular}{|l|l|l|l|l|}
\hline & N & Minimum & Maximum & Mean (SD) \\
\hline $\begin{array}{l}\text { Phoneme trained group } \\
\text { (PA) }\end{array}$ & 58 & 51 & 66 & $58.40(4.039)$ \\
\hline $\begin{array}{l}\text { Letter knowledge } \\
\text { trained group (LK) }\end{array}$ & 70 & 52 & 66 & $58.21(3.694)$ \\
\hline Control group (Control) & 53 & 50 & 65 & $58.75(3.941)$ \\
\hline
\end{tabular}

Educational Context. Preschool education in the Czech Republic covers ages 3 to 6 (sometimes even 7) years. In most cases children enter the first grade of primary school at the age of 6 . Letter learning is not a compulsory part of kindergarten classroom activities. However, the typical Czech pre-schooler may know some letter sounds but few if any letter names, the latter typically being the product of literacy training in first grade. Systematic training of phoneme awareness also is not a compulsory part of the preschool curriculum. Activities at the level of syllable awareness (syllable identification, rhyming) and phoneme awareness (identification of the first sound of the word) are included mainly during the final year of kindergarten. Generally, literacy-related kindergarten activities concentrate more on vocabulary, oral language skills and on grapho-motor skills. 


\section{Tests and procedures}

For the purpose of this study, we created and implemented a test battery to assess: knowledge of letter names and sounds, letter writing, phoneme awareness, very early reading skills and nonverbal IQ. Testing was carried out by a team of 5 research assistants, and tests were administered in a fixed order to all participants in all schools. Standardized measures were either not available (due to the relatively young age of the participants), or not suitable for the present study (e.g., available norms for the Raven's Matrices for the Czech population of preschool children were too old to be applicable; Kučerová-Husníková \& Gjuričová 1977). Nevertheless, in view of our relatively large and broadly selected sample, we are confident that the scores obtained are representative of typically developing children of this age.

\section{Nonverbal Ability}

As a screening measure of nonverbal intelligence Raven's Coloured Progressive Matrices were administered according to published guidelines. We report raw scores ranging from 0 to 36 points.

\section{Phoneme awareness}

To assess phoneme awareness, we used an adaptation of our Phoneme Isolation task (Caravolas et al., 2012; Hulme et al., 2005; Seidlová Málková, \& Caravolas, 2013), where the targeted skill is the isolation of an initial phoneme in a CVC nonword. For the purpose of this study, children repeated and isolated (pronounced aloud) the initial phoneme in a set of 50 nonwords, covering two tokens of each of 25 consonant phonemes in the Czech language. The test was presented in two blocks administered separately, however in one day. Each block consisted of items assessing 25 phonemes. All stimuli were phonologically legal and pronounceable in Czech. One point was awarded for each phoneme correctly isolated.

\section{Letter knowledge measures}

To assess letter knowledge we administered letter recognition and letter writing tasks, similar to those in Hulme et al. (2005).

In the Letter recognition task, children were asked to supply the sound and the name of each letter of the Czech alphabet. Letters were presented on 68 separate cards (font Times 72). The test was presented in two blocks of upper and lower case. The task was presented as much as possible in game-like manner to make it accessible for children as young as four years of age. The letters were presented in a fixed, not alphabetical, order. One point was awarded for each correctly named letter - either by its sound or its name. 
The Letter writing task was administered as a dictation of letter sounds of the 34 letter sounds of the Czech alphabet. Our aim was primarily to assess children's spontaneously acquired letter writing knowledge. The letters "W" and "Y", were dictated by their names because these letters' sounds could not be distinguished from those of "V" and "I". One point was awarded for each correctly spelled letter, reversals were not considered correct.

\section{Reading measure}

The One Minute Reading test (Caravolas, \& Volín, 2005; Caravolas, Volín \& Hulme, 2005) was used to assess reading skills. This is a standardized test for Czech primary school children, which measures single word reading speed of a graded word list for one minute. This test was included at Time 1 on the assumption that most children would be non-readers (as is typical for this age group in the Czech republic), or would only read a few single-letter words. This expectation was confirmed, but nevertheless, eleven children could read aloud words of two or more letters and were excluded from the study in order to control the potential confounding effects of reading ability (see also section Participants). Notably, among the remaining sample, reading ability did not increase significantly by the end of the interventions (T2) and hence was not used in further analyses. A reading efficiency score was obtained by summing each correctly and fluently read word over the one minute span. There are no published norms for this age group, hence we report raw scores.

The reliabilities of all measures are presented in Table 2. As can be seen, the measures generally proved to have high reliability, crucially so for the phoneme awareness and letter knowledge tasks. The One Minute Reading test showed lower reliability (calculated for the larger original sample) reflecting the near floor performance levels of the participants.

Table 2. Reliability of measures used, reported as Cronbach alpha or as an autocorrelation between $\mathrm{T} 1$ and $\mathrm{T} 2$ measures.

\begin{tabular}{|l|l|l|}
\hline Measure & Reliability (N) & T2 (post-test) \\
\hline & $T 1($ pre-test) & $0.990(189)^{\mathrm{a}}$ \\
\hline Phoneme isolation a & $0.987(189)^{\mathrm{a}}$ & $0.962(190)^{\mathrm{a}}$ \\
\hline Letter recognition- upper case a & $0.961(192)^{\mathrm{a}}$ & $0.938(190)^{\mathrm{a}}$ \\
\hline Letter recognition- lower case a & $0.930(192)^{\mathrm{a}}$ & $0.949(189)^{\mathrm{a}}$ \\
\hline Letter writing a & $0.956(189)^{\mathrm{a}}$ & -- \\
\hline One minute reading b & $0.614(188)^{\mathrm{b}}$ & -- \\
\hline Raven (nonverbal IQ) a & $0.718(192)^{\mathrm{a}}$ & - \\
\hline
\end{tabular}

Note: $\mathrm{a}=$ Cronbach alpha, $\mathrm{b}=$ correlation between T1 and T2 measure. 


\section{Intervention programmes}

Both intervention groups received 35 training lessons of 45-60 minutes (daily) throughout the last two months of the school year. During the intervention programmes, children assigned to the control group were attending regular class programmes with one of their usual teachers on a 'business as usual' basis in all participating schools. There are regularly two class teachers who share their time in the classroom during the day. At the most busy times of the day, both teachers are in the classroom. During the training procedures, one teacher from the class took the training and the other stayed in the classroom with the rest of the group. Both interventions were introduced within the framework of visits to a fairy tale land. Children in the PA intervention were visiting a "Land of Sounds", children in the LK intervention visited a "Letter Circus". Both interventions were undertaken in each participating school by the children's usual teacher (teachers). Each intervention group had its own classroom where the training took place, and each had its own materials (flipchart, magnetic board, folders, etc.). Teachers were informed that the intervention groups could not share training materials, and children were not to show their training materials to peers in other groups.

Teachers involved in the implementation of the training programmes were nominated by their schools and volunteered to provide the intervention. They received eight hours of training on the use of the materials three weeks before the intervention began, and were regularly supervised and supported by the research team throughout the intervention. Teachers recorded each session and monitored the presence of each child in lessons. Absenting children - with one or two day's absence - received extra training sessions to catch up with the rest of the intervention group.

\section{Phoneme awareness intervention}

The PA intervention programme consisted of two parts: a shorter syllable awareness component (approx. 10 lessons) and a longer phoneme awareness component, where the most important aspect of training was identification and isolation of specific phonemes presented in various words.

The content of this intervention was inspired by programmes originally constructed for children around 6 years of age (Hatcher, 2000; Mikulajová \& Dostálová, 2004;) but was adapted to be accessible for children of 4.5 years of age. Special attention was paid to word sound structure and to the salience of sounds (phonemes) to a child. The syllable or phoneme structure of a word was manipulated by using various tools (tokens, binds...). Each phoneme introduced during the programme was represented by a picture of a "Soundie", a little creature with butterfly wings resembling a child, whose name begins with the targeted phoneme. Each Soundie carried a picture on its wings of a word beginning with its phoneme (see Figure 1). 


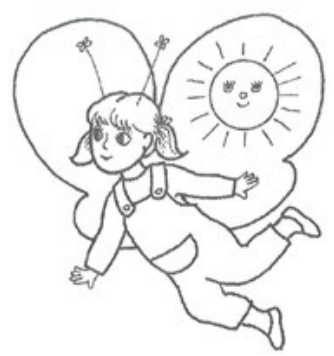

Figure 1. An example of the Soundie /s/ (picture reproduced with permission of the authors; Mikulajová \& Dostálová, 2004).

Twenty-four phonemes (the majority of Czech consonants) were introduced by the Soundies throughout the lessons. Various tasks including phoneme identification, phoneme categorisation or isolation were presented, combining paper and pencil and oral activities. Detailed information about the structure and the content of phoneme awareness training is provided in Box 1.

\section{Box. 1 The structure and content of the Phoneme Awareness programme:}

\begin{tabular}{|c|}
\hline 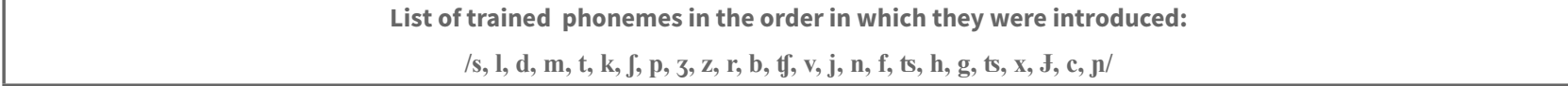 \\
\hline $\begin{array}{l}\text { Segmenting words ( } 2 \text { lessons): Activities aimed at the identification of the beginning, middle, and end parts of words, and explaining what it means } \\
\text { when we say "beginning, middle, and end part of the word". This positional concept was modelled by presenting a real-world analogue (for exa- } \\
\text { mple a train with a long row of carriages has got its beginning, middle and end parts). }\end{array}$ \\
\hline $\begin{array}{l}\text { Syllable awareness (7 lessons): Activities included syllable identification, syllable segmentation, and modelling syllables in words (tokens, schema), } \\
\text { as well as discrimination of short/long syllables, making up words according to a syllable schema, and syllable categorization. Mr. Syllable (intro- } \\
\text { duced as "an expert" in dividing words into syllables) was presented to help children to learn syllabification. Later, Mr. Long was introduced to help } \\
\text { children differentiate long and short syllables (i.e., vowels). This section contained lessons where children: }\end{array}$ \\
\hline $\begin{array}{l}\text { 1. Learned how to identify the syllable in a real word. The syllable was drawn out from a real word in a situation that was familiar to children. } \\
\text { Children were encouraged to imagine a playground in an arena with fans. Fans chanted and chanting was a model situation for modelling a } \\
\text { syllable. After that children learned to syllabify by clapping. Various activities practising syllable identification in real words varying in length } \\
\text { were provided. }\end{array}$ \\
\hline $\begin{array}{l}\text { 2. Syllable schema (a frame for each syllable written on a paper/paper card) was presented and children learned to "catch" syllables in a word } \\
\text { with this frame. Also children produced or made up words according to a particular syllable schema. For example: the word "teta" (aunt) was } \\
\text { presented by a frame comprising two syllables, later children looked for other words that would fit this frame: for example a word "koza" (goat). }\end{array}$ \\
\hline 3. Learned to differentiate short and long syllables, and to use a syllable schema for short and for long syllables. \\
\hline 4. Learned to use particular syllable schemata for devising or creating different words. \\
\hline $\begin{array}{l}\text { 5. Differentiated similar syllables. For example, the odd one out game was played: children heard three two- or three-syllable words. All words } \\
\text { began with the same phoneme, two with the same syllable and one with a different syllable. Children were looking for the one that began with } \\
\text { a different syllable (for example in the set / zelí- zima- země/, the second word was the odd one out.) }\end{array}$ \\
\hline
\end{tabular}


Phoneme awareness (20 lessons): Phonemes were introduced in groups of 4- 5 at a rate of 1 or 2 phonemes per lesson, and then one revision lesson for all 4/5 sounds. Each new phoneme was introduced by its associated "Soundie" from the Land of Sounds. The activities included:

1. Searching and differentiating words beginning with a particular phoneme: for example various pictures of objects were presented to the children who searched pictures representing words beginning with the target phoneme. Children collected these depicted objects for a particular Soundie.

2. Sounding out phonemes and coming up with words beginning with particular phoneme: for example children were asked to think about and say as many words beginning with particular phoneme as possible; pictures were presented and children tried to name the pictures and identify the beginning phoneme.

3. Identification of the beginning sound in a word: for example various words or even pseudowords were presented orally and children tried to guess, which Soundie would like the particular word.

4. Categorisation of words according to the initial phoneme: for example children played an odd one out game, where three short (one- or two-syllable) words were presented, two began with a same phoneme, the third began with a different one.

\section{Letter knowledge intervention}

In Czech culture, children who learn about letters spontaneously, through informal exposure to oral and written language, will typically learn letter sounds (Hulme et al., 2005). Knowledge of letter names is the product of educational practices or direct training. Teachers in our training programme focused primarily on teaching letter shapes, letter formation, and they tended to refer to letters by their alphabetic names. To maintain the playful character of the programme, each letter of the Czech alphabet was introduced as a circus figure. For this purpose we used the children 's book „Friends from the alphabet" (Petrák \& Malý, 2012) where all letters were drawn either as circus figures or were surrounded by the circus objects. Each letter was presented with a short rhyme emphasising the characteristics of its shape or in some cases only with a rhyme based on the letter name. Throughout the intervention programme, paper sheets were used for colouring letters, for fixing the shape of each letter, and for practising letter writing. The training programme included all alphabet letters, with the exception of letters using diacritics.

Letters were introduced in groups of 5 or 6 . First, each letter from the group was introduced in 1 lesson, after approximately 5, individual letter lessons, a revision lesson was provided for the letter set. Exercises reviewing all of the letters were also introduced toward the end of the programme. Teachers used a variety of activity sheets, including letter rhymes, colouring pictures of words beginning with target letters, writing each letter, and wooden letters.

Detailed information about the structure and the content of letter knowledge programme is provided in Box 2. 


\section{Box. 2 The structure and the content of Letter Knowledge programme:}

\section{List of trained letters in the order in which they were introduced:}

A, B, C, D, E, F, G, H, CH, I, Y, J, K, L, M, N, O, Q, P, R, S, T, U, V, W, Z, X

1. Each lesson introducing a new letter had this structure:

2. The name and shape of the letter from the book were introduced.

3. Teacher read a short rhyme describing the letter.

4. Teacher encouraged children to draw the letter (paper sheets for each child provided).

5. Teacher provided paper and pencil exercises for practicing each trained letter as described above (e.g., colouring, tracing, and games making up words that begin with this letter).

6. Revision lessons contained games and exercises aimed at the recognition or writing of taught letters. 
Example of the structure of exercises for letter "E":

- The picture of a letter "E" was provided, the letter was presented as a circus clown

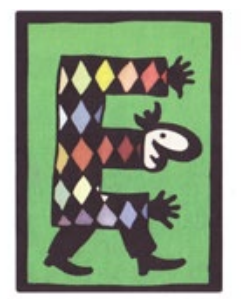

Tyale, dalir balek jeat

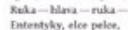

Figure 2. Example of the training material for the letter knowledge recognition activities - picture of the letter E (from Petrák \& Malý, 2001).

- The short rhyme for the letter was provided. The wooden model of the letter was presented and children named the letter. Children repeated the name of the letter.

- Letter writing was practiced: An exercise with the cues guiding the writing of the letter was provided. Then children were trying to write the letter themselves without cues.

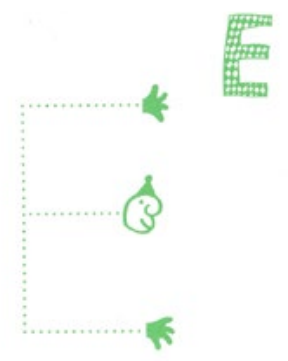

Figure 3. Example of the training material for the letter writing activities- paper sheet for practising letter "E" writing (from Petrák \& Malý, 2001).

- Children used a colouring sheet devoted to the letter. This activity may be followed by an exercise, where children look for words beginning with the target letter.

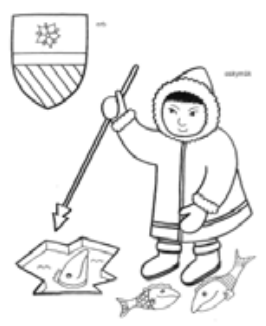

Figure 4. Example of the training material used in letter knowledge training- colouring paper sheet (example from Skořepová, 2007). 


\section{Results}

\section{Preliminary analyses and descriptive statistics}

Table 3 shows the means and standard deviations for all measures at pre-test (T1) and for phoneme awareness and letter knowledge at immediate post-test (T2).

Table 3. Raw mean scores and standard deviations of the control variables (T1), and the main outcome variables of phoneme awareness and letter knowledge measured before the intervention (T1) and at the end of intervention (T2).

\begin{tabular}{|c|c|c|c|c|}
\hline & $\begin{array}{l}\text { Phoneme Awareness } \\
\text { Training Group } \\
\mathrm{n}=58\end{array}$ & $\begin{array}{l}\text { Letter Knowledge } \\
\text { Training Group } \\
\text { n=70 }\end{array}$ & $\begin{array}{l}\text { Untreated Control } \\
\text { Group } \\
n=53\end{array}$ & \\
\hline Measure & $M(S D)$ & $M(S D)$ & $M(S D)$ & \\
\hline \multicolumn{5}{|l|}{ Phoneme awareness } \\
\hline Phoneme isolation T1 & & $22.60(18.80)$ & $18.43(17.90)$ & $14.76(19.91)$ \\
\hline Phoneme isolation T2 & & 32.14(19.91) & $31.51(19.62)$ & $20.17(19.67)$ \\
\hline \multicolumn{5}{|l|}{ Letter knowledge } \\
\hline Letter recognition* $\mathrm{T} 1$ & & $9.05(10.12)$ & $9.94(11.55)$ & $8.89(11.77)$ \\
\hline Letter recognition* T2 & & $11.91(13.47)$ & 19.70(15.37) & $12.05(14.97)$ \\
\hline Letter writing T1 & & $4.86(5.98)$ & $5.03(7.32)$ & $6.32(7.32)$ \\
\hline Letter writing T2 & & $5.72(5.48)$ & $9.53(7.30)$ & $6.43(6.86)$ \\
\hline \multicolumn{5}{|l|}{ Reading } \\
\hline One minute reading $T 1$ & & $0.34(0.72)$ & $0.44(0.97)$ & $0.40(0.81)$ \\
\hline \multicolumn{5}{|l|}{ Nonverbal IQ } \\
\hline Raven matrices T1 & & $15.74(4.10)$ & $14.27(4.26)$ & $14.55(4.66)$ \\
\hline
\end{tabular}

* Letter recognition was calculated as a composite score of knowledge of upper and lower cases of each letter.

The ensuing analyses addressed three main questions regarding the development of phoneme awareness (PA) and letter knowledge (LK). First, for insights into the nature of each skill's development, we investigated the distributional properties of children's PA and LK scores prior to and after the intervention, as a function of their group. Second, to assess the impact of the two training programmes, we assessed gains in each group from T1 to T2, as well as their T2 scores relative to the untrained control group. Finally, in a series of ANCOVAs, we compared attainments at T2 in phoneme awareness and letter knowledge, while controlling for group differences in these skills at baseline, and we investigated their interrelationships. 


\section{Distributions of phoneme awareness and letter knowledge skills}

Before interpreting any pre-test and post-test results, it was important to note the structure of children's performance. Figure 5 shows histograms of performance on the phoneme isolation task in each experimental group before (upper panels) and after (bottom panels) the intervention. The pattern of scores indicates a bimodal distribution, which is evident across all groups at pre-test. That is, at $\mathrm{T} 1$, approximately $40 \%$ of the children across groups were not capable of carrying out this task at all (scoring 0), while almost half (46\%) showed a relatively normal distribution in the range between 20 and 50 points. Interestingly, after seven weeks (T2), all groups showed improvement on the PA task but nevertheless, the bimodal distribution remained visible (most clearly in the untrained group). At closer inspection, as anticipated, the PA and LK training had a greater impact on moving children (over $70 \%$ of each sample) into the range of good-to-excellent PA proficiency (20-50 points), relative to the untrained controls, of whom $46 \%$ were scoring in the proficient range. At the lower ability end, $20 \%$ of the PA- and LK-trained groups and 33\% of the Control group were still unable to do the task at T2; notably, the Control group showed the largest number of children moving from no ability (zero) to low-moderate ability levels (2-19 points) at T2. Thus, it seems that at approximately 4.5 years of age, children who have not yet received any systematic literacy-related instruction divide roughly evenly into those who can perform phonemic manipulations relatively easily and those who find this very difficult. We return to this issue in the Discussion.
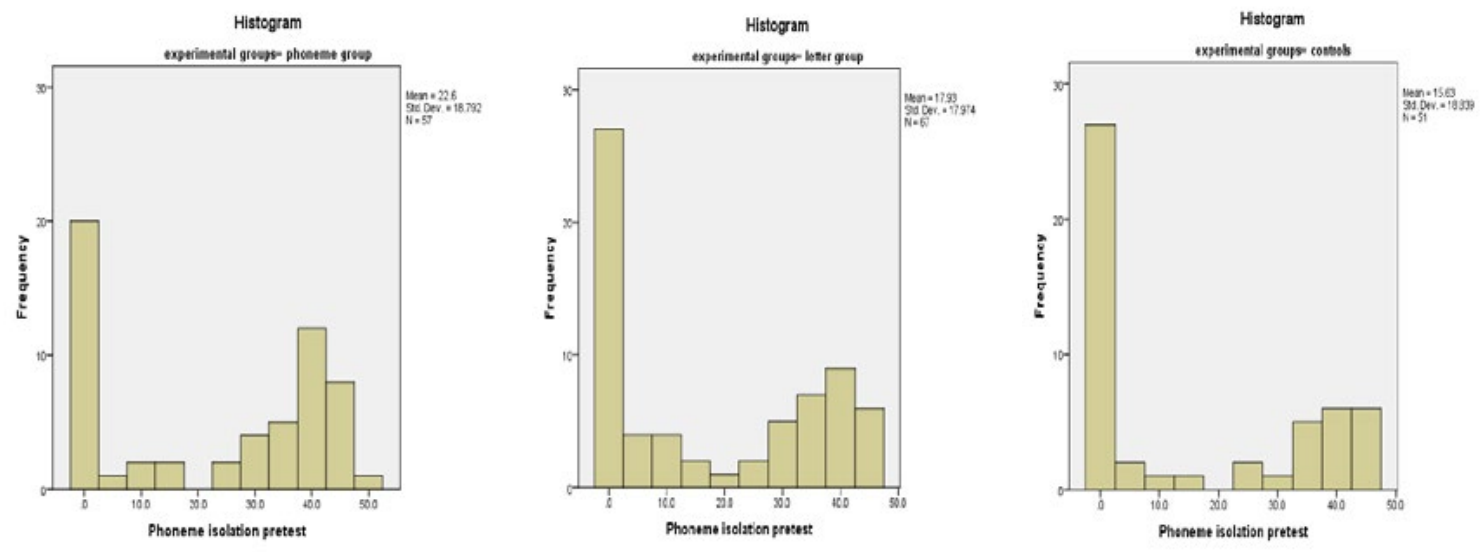

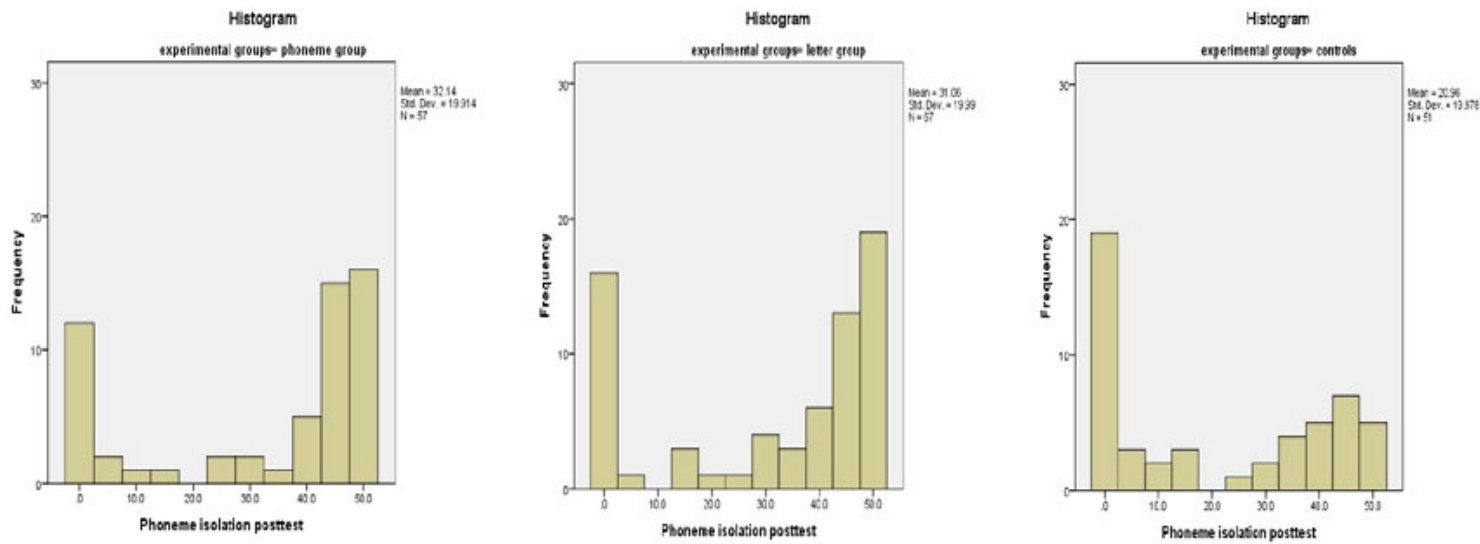

Figure 5. Histograms of performance in Phoneme isolation in all experimental groups at pretest (top panel) and post-test (bottom panel)

We next inspected the distributions on the letter recognition task, as illustrated in Figure 6. In contrast to phoneme isolation, the distribution of performance in the letter recognition task at pretest was positively skewed, showing the majority of children in each group to know no letters or only a few prior to intervention (top panel). At a post-test (bottom panel), the distributional structure in the PA and the Control groups changed very little, while the structure in the LK trained group was moving toward a normal, unimodal distribution. This suggests, that unlike for phoneme awareness, the emergence of letter knowledge is rather monolithic, and is probably more strongly subject to direct explicit instruction for its growth.
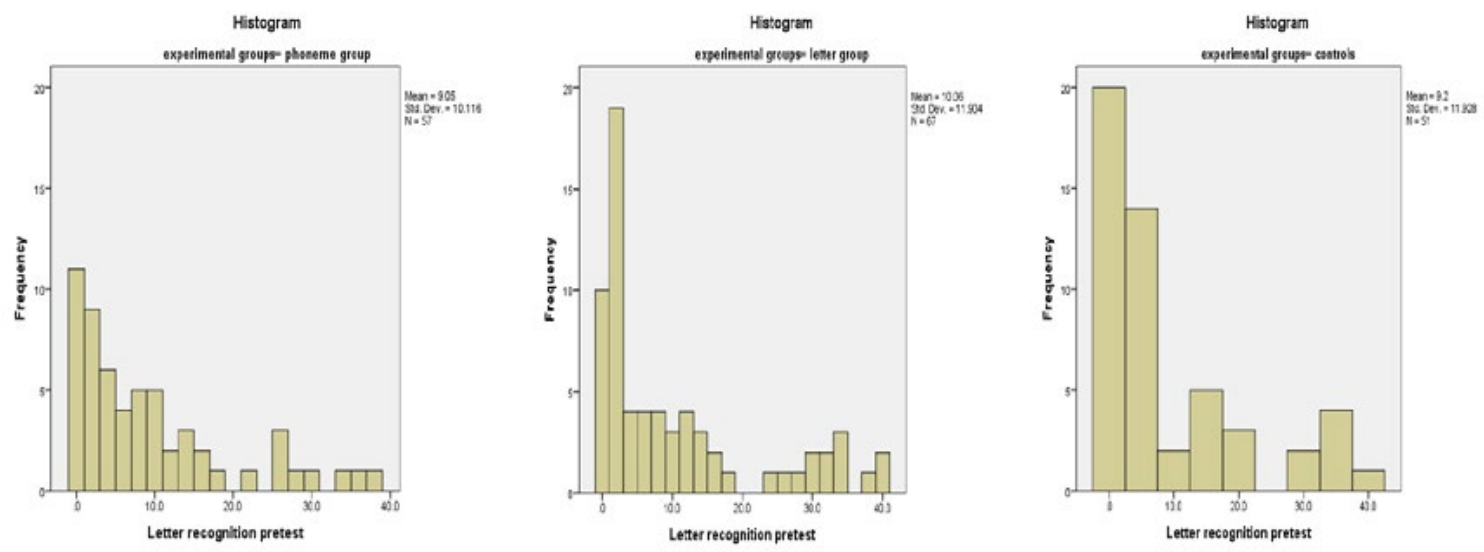

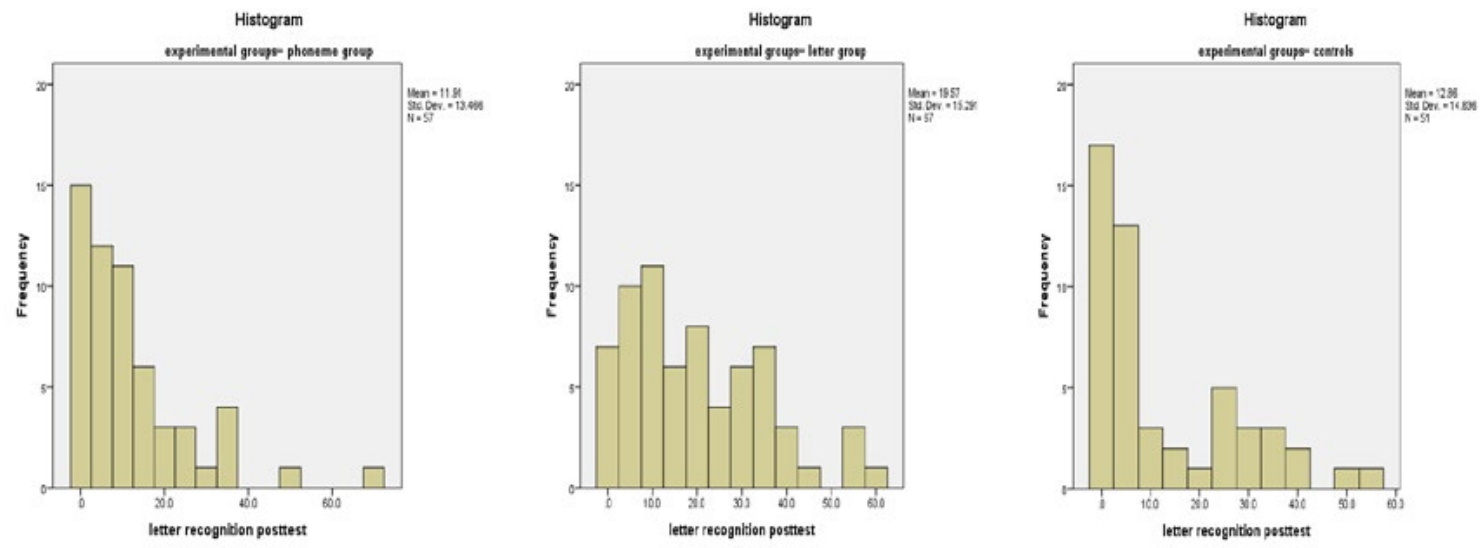

Figure 6. Histograms of performance in letter recognition in all experimental groups at pretest (top panel) and post-test (bottom panel).

\section{Effectiveness of training and developmental interrelationship of letter knowledge and phoneme awareness}

Prior to assessing gains in each of the abilities of interest, we first compared the groups on baseline performances of Phoneme Isolation, Letter Recognition, and Letter Writing, respectively. While the data on the above measures were not normally distributed, the variances were homogeneous over tasks and over groups (Levene's statistic $p$ values for Phoneme Isolation $=.66$, for Letter Recognition $=.34$, Letter Writing = .48), and our sample sizes were adequately large; therefore, we conducted one-way ANOVAs (which are robust to non-normality of scores) (Field, 2000). These analyses revealed that the groups were not significantly different from each other on Phoneme Isolation $(F(2,175)=2.15, p>.10)$, on Letter Recognition $(F(2,178)=0.11, p>.89)$, or on Letter Writing ability $(F(2,175)=.895, p>.40)$ at the start of the study.

Next, to assess the effectiveness of each training programme, we conducted paired samples t-tests for each training group (PA and LK, respectively) testing the statistical differences between pre- and post-test scores. Results of these analyses revealed significant gains in phoneme awareness performance in the PA training group $(t(56)=-6.240, p<.001)$, and, significant gains in letter recognition and letter writing in the LK trained group (letter recognition: $t(68)=-9.291, p<.001$; letter writing: $t(66)=-6.898, p<.001)$. To assess the extent to which the observed gains arose as a consequence of each bespoke training programme, we also tested the differences in attainments at post-test (T2) between the Control group and each experimental group using independent samples t-tests. The PA trained group performed significantly better than the Control group on phoneme isolation $(t(108)=-2.840, p=.005)$, while they did not differ on either letter knowledge task ( $p s>.55)$. The LK trained group performed significantly better than the Control group on both letter knowledge measures (letter recognition: $t(119)=2.484, p=.014$; letter writing: $t(117)=2.351, p=.020$ ). The LK trained group also performed better than the Control group on phoneme isolation $(t(118)=2.586, p=.011)$. 
The above results demonstrate that each training programme was effective in raising the targeted skill in each group, relative to pre-training levels, and relative to the untrained Control group. However, as illustrated in the bottom panels of Figures 5 and 6 , in each intervention group, some children responded less well to the training. We return to the latter issue in the Discussion.

Furthermore, the results showed that, at post-test, each training procedure had a different impact on accelerating development of the untrained skill (i.e. phoneme awareness or letter knowledge). That is, children in the LK training group appeared to make gains at T2 in phoneme awareness, although they did not undergo explicit PA training. In contrast, it was not clear whether children in the PA training group made gains in the untrained letter knowledge ability. To examine this issue more directly, we conducted one-way analyses of covariance on phoneme awareness outcomes and letter knowledge (letter recognition, letter writing) outcomes, respectively, as a function of group. We adopted ANCOVA because our data met the assumption of homogeneity of variance, and because this method is tolerant of moderate deviations from normality (Field, 2013; Glass, Peckham, \& Sanders, 1972, Lix, Keselman, \& Keselman, 1996). Furthermore, this allowed us to test differences between the experimental and Control groups' gains at post-test on the dependent T2 measures while simultaneously controlling children's pre-test (baseline) performance on all three measures, as well as to estimate the possible predictive relationships between PA and LK at T1 and PA and LK at T2. In each of three analyses, scores on T1 phoneme isolation, letter recognition and letter writing were entered as covariates. Sidak correction was used for post hoc comparisons.

The ANCOVA on T2 phoneme awareness revealed significant differences between training groups $(F=5.937,(2,169), p=.003)$. The Sidak post hoc tests confirmed that while the PA- and LK-trained groups did not differ significantly from each other ( $(=.576)$, the Control group remained significantly weaker than the LK group ( $p=.002)$, and marginally weaker than the PA group ( $p=.083)$. Interestingly, across all groups, only phoneme awareness at baseline (covariate) contributed to the growth of phoneme awareness at T2 $(p<.001)$, while the influence of earlier letter recognition and letter writing seemed to be unimportant ( $p=.662$ for letter recognition, and $p=.907$ for letter writing). The ANCOVA on letter recognition at T2 revealed a significant difference between groups ( $F=20.172$ $(2,170), p<.001)$. The Sidak tests confirmed that the LK group performed significantly better than the Control group $(p<.001)$ and the PA trained group $(p<.001)$, while the latter two groups did not differ from each other $(p=.759)$. In all groups, children's baseline levels of both letter knowledge measures (letter recognition: $p<.001$; letter writing $p=.001$ ) as well as in phoneme awareness $(p<.001)$ had significant impacts on T2 letter recognition performance. Finally, the ANCOVA on letter writing generated much the same pattern of results as that for letter recognition. Thus, a main effect of group was obtained ( $F=20.421,(2,168), p<.001)$, which was due to the better T2 performance of the LK group relative to the PA $(p<.001)$ and the Control $(p<.001)$ groups. Also, T1 measures of both letter knowledge measures (recognition: $p<.001$; writing: $p<.001$ ) together with phoneme awareness $(p<.001)$ contributed to the growth of letter writing ability at T2. 


\section{Discussion and Conclusion}

This study with Czech 4.5-year-old pre-schoolers enabled us to address issues regarding (1) the natural developmental (perhaps incidentally acquired) patterns of phoneme awareness and letter knowledge in children who have not yet received any formal tuition in these skills, (2) the effectiveness of specific training programmes on the further growth of both skills, and (3) the relative importance of phonemic and letter skills, measured prior to training, on their subsequent (albeit short-term) growth. We considered the findings against the dominant theoretical frameworks proposed in the literature. The first interesting finding revealed visibly different distributions in the early development of phoneme awareness and letter knowledge (Figures 5, 6). That is, prior to intervention, all three randomly assigned groups in fact comprised two, roughly equally sized subgroups of ability in phoneme awareness: 40\%-50\% of children were clearly showing good phoneme awareness, but almost as many were struggling to do the task. What is more, while the vast majority of children who had received two months of daily training in phoneme awareness or in letter knowledge showed marked improvements after training, some $20 \%$ of these groups remained unable to isolate initial phonemes. It seems likely that many of these 'treatment non-responders' are those children who carry a risk of developing literacy difficulties in the primary grades. The progress of the Control group between baseline and post-test is also of interest here because it demonstrates that even without training in phoneme awareness or letter knowledge, a substantial number can progress from complete inability to some measurable levels of phoneme awareness; however the T2 scores of the Control group also suggest that without direct tuition in phoneme awareness, relatively few children (7\% in the present sample) progress from low to good/excellent levels of PA proficiency. Bimodal distributions, such as those observed here have been noted in previous studies (e.g., review by Bentin, 1992), and we interpret this finding to be consistent with the view that phoneme awareness is a skill naturally arising from oral language abilities (i.e., in the absence of explicit teaching), but which can be significantly accelerated through explicit phoneme-based and/or letter-sound based training. Moreover, variations in its development, including individuals' ability to respond to explicit PA (or letter-sound) training, may be at least as strongly constrained by innate cognitive/language factors as by the environmental influence of direct instruction (e.g., Fowler, 1991). In this view, children for whom phonemic awareness does not 'come naturally' even with explicit training may well be those with phonological processing or broader language difficulties, who will later face difficulties in literacy acquisition (e.g., Carroll, Snowling, Stevenson, \& Hulme, 2003). Unfortunately, we did not include broader language measures that would enable us to test the hypothesis that children who were slower to acquire phoneme awareness also had more slowly developing oral language skills; this will be a provision for future investigations. 
In contrast, letter knowledge - i.e., knowledge of a human artefact - was unimodally distributed, and seemed to depend much more strongly on direct instruction. We found no evidence of subgroups on this measure at baseline or after the intervention phase, and only the LK training group progressed from a positively skewed to a more normal distribution of outcomes post intervention. It might be argued that removing the 11 children with extremely high letter knowledge scores at the outset precluded the detection of subpopulations on the letter recognition measure, however, this group represented 3 or 4 individuals per experimental group, and they could safely be considered extreme outliers, not children comprising a sizeable subpopulation.

The second question of interest in the present study concerned the effectiveness of PA training or raising PA levels and of LK training on raising letter knowledge levels among Czech 4.5-year-olds. Each training programme had a positive direct effect on raising skill levels relative to baseline as well as to untrained controls, however, these 35-lesson programmes were not sufficiently effective to bring all children to measurable levels of performance. Some children simply seemed to not respond to the intervention. We considered whether the variations in children's readiness to respond to each intervention could be accounted for by variations in chronological age, but found no strong evidence of this on the basis of correlations between age and gain scores from T1 to T2, either for the PA group ( $r=-.14$ ) or the LK group ( $r=-.06$ ). Nevertheless, other age-related variables may have been at play, not least variations in the maturity of attentional and/or memory capacities, and such measures should be included in future studies to help to elucidate the causes of individual differences in 'response to intervention'.

The third key question of the present study concerned the nature of the relationship between phoneme awareness and letter knowledge, and whether our data would provide support for one of the prominent causal hypotheses, that is the 'letter knowledge first' or the 'dual foundation' hypothesis. We did not consider the 'reading first' hypothesis in this population of non-readers. In this respect, the results of the present investigation were broadly consistent with the dual foundation hypothesis. That is, while at this stage of pre-literacy, we found no evidence of a reciprocal relationship between phoneme awareness and letter knowledge, we did find clear evidence in the ANCOVAs, that the growth of letter knowledge (even when not trained) depended on earlier letter knowledge as well as on phoneme awareness; each skill being a separate contributor. In contrast, in all groups, the growth of phoneme awareness at T2 was only predicted by baseline levels of phoneme awareness, and not by letter knowledge. This finding argues against the view that phoneme awareness can only emerge as a consequence of letter knowledge (e.g., Castles \& Coltheart, 2004).

In addition to these correlational findings, the analyses of the interventions revealed further interesting results. Importantly, LK training, which in our study concentrated primarily on letter forms and shapes but also included spontaneous reference to the letters by their names/sounds and some explicit letter naming activities, was associated with T2 gains not only in letter knowledge itself, but also in phoneme awareness. While this result is in line with a number of previous studies (e.g., Ball \& Blachman, 1991; Hatcher et al., 1994; Hulme et al., 2012), it is at odds with that of Castle's et al. (2009), 
whose letter training programme focussed specifically on the nonverbal aspects of letter knowledge. The inclusion of letter-sound/name associations in the present LK intervention unfortunately precluded us from teasing apart the specific influences of learning the visual and motor features of letters from their phonological associations, and this awaits a further study. On the other hand, the PA intervention, which completely excluded phoneme-letter associations revealed only the expected gains in phoneme awareness and no benefits to incidental letter learning.

Finally, we emphasize that our findings indicate that while LK training, which includes letter-sound and letter-name teaching, is associated with gains in phoneme awareness, this does not mean that letter sound knowledge causes phoneme awareness to emerge. On the contrary, the differential patterns of PA and LK skill distribution among these preliterate learners as well as the ANCOVAs suggested that phoneme awareness is a separately arising ability and an independent predictor of growth in letter knowledge (recognition and writing), and this was true in every group, regardless of training. However, it would seem that while LK training can ,spontaneously' increase growth in phoneme awareness, PA training cannot spontaneously augment growth in letter knowledge. Although learners' phoneme awareness abilities partly constrain the development of letter knowledge, it seems that in order to make measurable gains in learning, they require explicit letter-sound instruction.

\section{Acknowledgements}

Preparation of this paper was funded by Czech Science Foundation. It is a constituent part of outputs of grant project for the Faculty of Humanities Charles University in Prague P407/13-25625S "Phoneme awareness and letter knowledge training - its developmental relationship and influence to the early literacy".

Note: Both authors contributed equally to the writing of this paper. 


\section{References}

Adrián, J., Alegria, J., \& Morais, J. (1995). Metaphonological abilities of Spanish illiterate adults. International Journal of Psychology, 30(3), 329-351.

Barron, R. W. (1998). Proto-literate knowledge: Antecedents and influences on phonological awareness and literacy. In C. Hulme, \& R. M. Joshi (Eds.), Reading and spelling: Development and disorders (pp. 153-175). Mahwah, N.J.: Lawrence Erlbaum Associates.

Ball, E. W., \& Blachman, B. A. (1991). Does phoneme awareness training in kindergarten make a difference in early word recognition and developmental spelling? Reading research quarterly, 26, 4966.

Bentin, S. (1992). Phonological Awareness, Reading and reading acquisition: A survey and appraisal of current knowledge. Haskins Laboratories Status Report on Speech Research, SR-111 / 112. 167180.

Bradley, L., \& Bryant, P. E. (1983). Categorizing sounds and learning to read: A causal connection. Nature, 301, 419-521.

Burgess, S., \& Lonigan, C. (1998). Bidirectional relations of phonological sensitivity and prereading abilities: Evidence from a preschool sample. Journal of Experimental Child Psychology, 70(2), 117141.

Caravolas, M., \& Bruck, M. (1993). The effect of oral and written language input on children's phonological awareness: A cross-linguistic study. Journal of Experimental Child Psychology, 55(1), 1-30.

Caravolas, M., Hulme, C., \& Snowling, M. J. (2001). The foundations of spelling ability: Evidence from a 3-year longitudinal study. Journal of Memory and Language, 45(4), 751-774.

Caravolas, M., \& Landerl, K. (2010). The influences of syllable structure and reading ability on the development of phoneme awareness: A longitudinal, cross-linguistic study. Scientific Studies of Reading, 14(5), 464-484.

Caravolas, M.,Lervåg, A., Defior, S., Seidlová Málková, G., Hulme, CH. (2013). Different patterns, but equivalent predictors, of growth in reading in consistent and inconsistent orthographies. Psychological Science, 24, 8, 1398-1407.

Caravolas, M., Lervåg, A., Mousikou, P., Efrim, C., Litavský, M., Onochie-Quintanilla, E., Salas, N., Schöffelová, M., Defior, S., Mikulajová, M., Seidlová Málková, G., Hulme, CH. (2012). Common patterns of prediction of literacy development in different alphabetic orthographies. Psychological Science, 23(5), 678-686.

Caravolas, M., \& Samara, A. (2015). Learning to read and spell words in different writing systems. In A. Pollatsek and R. Treiman (Eds.) The Oxford Handbook of Reading. Oxford University Press.

Caravolas, M., \& Volín, J. (2005). Baterie diagnostických testů gramotnostních dovedností pro žáky 2. až 5. ročníku ZŠ. Praha: Institut pedagogicko-psychologického poradenství. 
Caravolas, M., Volín, J., \& Hulme, C. (2005). Phoneme awareness is a key component of alphabetic literacy skills in consistent and inconsistent orthographies: Evidence from Czech and English children. Journal of experimental child psychology, 92(2), 107-139.

Carroll, J., Snowling, M. J., Stevenson, J., \& Hulme, Ch. (2003) The development of phonological awareness in pre-school children. Developmental Psychology 39, 913-923.

Castles, A., \& Coltheart, M. (2004). Is there a causal link from phonological awareness to success in learning to read? Cognition, 91(1), 77-111.

Castles, A., Coltheart, M., Wilson, K., Valpied, J., \& Wedgwood, J. (2009). The genesis of reading ability: What helps children learn letter-sound correspondences? Journal of experimental child psychology, 104(1), 68-88.

Cossu, G., Shankweiler, D., Liberman, I. Y., Katz, L., \& Tola, G. (1988). Awareness of phonological segments and reading ability in Italian children. Applied Psycholinguistics, 9(01), 1-16.

Duncan, L., Cole, P., Seymour, P., \& Magnan, A. (2006). Differing sequences of metaphonological development in French and English. Journal of Child Language, 33, 369-399.

Fowler, A. E. (1991). How early phonological development might set the stage for phoneme awareness. In Brady, S. A. \& Shankweiler, D. P. (Eds.) Phonological Processes in Literacy: A tribute to Isabelle Y. Liberman (pp. 97-117). Mahwah: Lawrence Erlbaum Associates, Incorporated.

Gillon, G. T. (2004). Phonological awareness. From research to practice. New York: The Guilford Press.

Glass, G. V., Peckham, P. D., \& Sanders, J. R.. (1972) Consequences of failure to meet assumptions underlying fixed effects analyses of variance and covariance. Review of Educatioanl Research, 42, 237-288.

Hatcher, P. (2000). Sound linkage. London: Whurr Publishers, $2^{\text {nd }}$ edition.

Hatcher, P., Hulme, C., \& Ellis, A. W. (1994). Ameliorating early reading failure by integrating the teaching of reading and phonological skills: The phonological linkage hypothesis. Child Development, 65(1), 41-57.

Hulme, C., Bowyer-Crane, C., Carroll, J. M., Duff, F. J., \& Snowling, M. J. (2012). The causal role of phoneme awareness and letter-sound knowledge in learning to read combining intervention studies with mediation analyses. Psychological Science, 23(6), 572-577.

Hulme, C., Caravolas, M., Málková, G., \& Brigstocke, S. (2005). Phoneme isolation ability is not simply a consequence of letter-sound knowledge. Cognition, 97(1), B1-B11.

Johnston, R., Anderson, M., \& Holligan, C. (1996). Knowledge of the alphabet and explicit awareness of phonemes in pre-readers: The nature of the relationship. Reading and Writing, 8(3), 217-234.

Kučerová-Husníková, P., \& Gjuričová, Š. (1977). Př́ručka: Barevné progresivní matice. Bratislava: Psychodiagnostika. 
Levin, I., Patel, S., Margalit, T., \& Barad, N. O. A. (2002). Letter names: Effect on letter saying, spelling, and word recognition in Hebrew. Applied Psycholinguistics, 23(02), 269-300.

Liberman, I., Shankweiler, D., Fischer, F., \& Carter, B. (1974). Explicit syllable and phoneme segmentation in the young child. Journal of Experimental Child Psychology, 18(2), 201-212.

Lix, L. M., Keselman, J. C., \& Keselman, H. J. (1996). Consequences of assumption violations revisited: A quantitative review of alternatives to the one-way analysis of variance $\mathrm{F}$ test. Review of Educatioanl Research. 66, 579-619.

Lukatela, K., Carello, C., Shankweiler, D., \& Liberman, I. (1995). Phonological awareness in illiterates: Observations from Serbo-Croatian. Applied Psycholinguistics, 16(4), 463-488.

Mikulajová, M., \& Dostálová, A. (2004). V krajině hlásek a slov. Trénink jazykových schopností podle D. B. Elkonina. Bratislava: Dialóg.

Morais, J., Cary, L., Alegria, J., \& Bertelson, P. (1979). Does awareness of speech as a sequence of phones arise spontaneously? Cognition, 7(4), 323-331.

Muter, V., Hulme, C., Snowling, M., \& Taylor, S. (1997). Segmentation, not rhyming, predicts early progress in learning to read. Journal of Experimental Child Psychology, 65(3), 370-396.

Petrák, F., \& Malý, R. (2012) Kamarádi z abecedy. Host: Praha.

Read, C., Zhang, Y., Nie, H., \& Ding, B. (1986). The ability to manipulate speech sounds depends on knowing alphabetic writing. Cognition, 24(1-2), 31-44.

Seidlová Málková, G., \& Caravolas, M. (2013). Baterie testů fonologických schopností, BTFS. Praha: Národní ústav pro vzdělávání.

Skořepová, K. (2007). Abeceda - naučné omalovánky. Praha: ProART s.r.o.

Treiman, S., Jackiw, R., \& Gross, D. J. (2015). Lectures on current algebra and its applications. Princeton University Press.

Wimmer, H., Landerl, K., Linortner, R., \& Hummer, P. (1991). The relationship of phonemic awareness to reading acquisition: More consequence than precondition but still important. Cognition, 40 (3), 219-249.

Ziegler, J., \& Goswami, U. (2005). Reading acquisition, developmental dyslexia, and skilled reading across languages: A psycholinguistic grain size theory. Psychological Bulletin, 131(1), 3-29. 